\title{
Assessment of anti bacterial, anti inflammation and wound healing activity in Wistar albino rats using green silver nanoparticles synthesized from Tagetes erecta leaves
}

\section{S. IruthayaKalai Selvam*}

Post Graduate and Research Centre of Zoology, Jayaraj Annapackiam College For Women (Autonomous), Periyakulam, Theni District-625601 (Tamil Nadu), India

\section{S. Marian Bara Joicesky}

Post Graduate and Research Centre of Zoology, Jayaraj Annapackiam College For Women (Autonomous), Periyakulam, Theni District-625601 (Tamil Nadu), India

\section{A. Amolorpava Dashli}

Post Graduate and Research Centre of Zoology, Jayaraj Annapackiam College For Women (Autonomous), Periyakulam, Theni District-625601 (Tamil Nadu), India

\section{A. Vinothini}

Post Graduate and Research Centre of Zoology, Jayaraj Annapackiam College For Women (Autonomous), Periyakulam, Theni District-625601 (Tamil Nadu), India

\section{K. Premkumar}

Department of Biomedical Science, Bharathidasan University, Tiruchirapalli-620024 (Tamil Nadu), India

*Corresponding author. Email: kalai.akila@gmail.com

\section{Article Info}

https://doi.org/10.31018/ jans.v13i1.2519

Received: January 27, 2021

Revised: March 7, 2021

Accepted: March 12, 2021

\section{How to Cite}

Selvam, S. I. et al. (2021). Assessment of anti bacterial, anti inflammation and wound healing activity in wistar albino rats using green silver nanoparticles synthesized from Tagetes erecta leaves. Journal of Applied and Natural Science, 13(1): 343 - 351. https://doi.org/10.31018/jans.v13i1.2519

\begin{abstract}
Silver nanoparticles synthesized from plant material have superior bioactivities. The purpose of this current study was to synthesis, characterize and to explore the bioactive efficacy of silver nanoparticles (Ag-NPs) using aqueous leaf extract of Tageteserecta. The biosynthesized Ag-NPs were characterized using ultraviolet-visible spectroscopy, Fourier transform infrared spectroscopy (FTIR), X-ray diffraction and Scanning electron microscopy. Ag-NPs were studied for in-vivo anti-inflammatory and wound healing activities performed in female Wistar albino rats. UV -Vis absorption spectrum of the T.erecta leaves extract was obtained at $428 \mathrm{~nm}$ due to excitation of surface plasmon vibration in nanoparticles and confirms the synthesis of silver nanoparticles. The FTIR analysis showed the presence of sulfate, alkene and alcohol in the AgNP of T.erectaleaves. The average crystallite size of AgNP synthesized was found to be $27.2 \mathrm{~nm}$. The spherical silver grain of $15.5 \mathrm{~nm}$ average size has been depicted with high-resolution scanning electron microscopy. Maximum activity $(15 \mathrm{~mm})$ of T.erecta leaves silver nanoparticles was observed against Salmonella typhi $(15 \mathrm{~mm})$ followed by Escherichia coli $(12 \mathrm{~mm})$. Ag-NPs exhibited significant wound healing activity and anti-inflammatory activity in carrageenan-induced paw volume tests performed in female Wistar albino rats. Colloidal Ag-NPs can be synthesized by simple, nonhazardous methods, and biosynthesized Ag-NPs using T.erectaleaves extract have significant therapeutic properties. This work evidently confirmed that silver nanoparticles mediated T.erecta could be considered as a potential source for anti-inflammatory and wound healing drug.
\end{abstract}

Keywords: Anti-inflammatory activity, Bactericidal activity, Green synthesis, Silver nanoparticles, Tagetes erecta, Wound healing activity

\section{INTRODUCTION}

Silver nanoparticles are extensively applied as nanomedicine in the field of pharmacology, cardiology, dermatology, dentistry, Anti-inflammatory, disease detec- tion, diagnosis, drug delivery, biomaterials and devices coatings. They also act as wound healing as well as antimicrobial agents (Jasminka Talapkoet al., 2020, Burduset al., 2018, Baygar et al., 2018, Wang et al., 2017). Currently, due to their broad-spectrum of antimi- 
crobial activity they are applied in the medical field such as in regeneration materials (Burduset al., 2018),wound dressings, artificial implantation, antitumor drug carriers (Haider and Kang 2015, Liao et al., 2019), antibacterial vaccines, implantable medical devices (Wang et al., 2017) and also improve the development of textile and food product. In day to day life many silver-based air/ waters filtration, animal husbandry, textile materials, food packaging, etc. are used (Deshmukh et al.,2019).

Silver nanoparticles significantly used in therapy rather than diagnostic procedures due to their antimicrobial action (Mathur et al., 2018). Many scientific studies have proven the bactericidal and inhibitory activity of silver on pathogenic microorganisms (Dakalet al., 2016). Silver is effectual against a variety of microbes like bacteria, viruses and fungi. Hence silver has an advantage and enormous scope of activity over the majority of other antimicrobials (Mcdonnell and Russell 1999). The efficient activity of silver nanoparticles depends on their dimension, shape, colloidal state, charge, concentration, and surface coatings (Wei et al.,2015). Small diameter (10 and $15 \mathrm{~nm}$ ) Ag nanoparticles have greatest antimicrobial activity than the larger diameter (50 nm) (Beythet al., 2015, Shang et al.,2014). Wound management is an important factor in medical care due to traumatic injuries and the increasing incidence of chronic wounds such as diabetic ulcers, varicose ulcers, and pressure sores, and aging populations who exhibit less wound healing capacity (Blacklowet al., 2019, Mihai et al., 2019). Biopolymers in combination with nanoparticles which has potential antimicrobial, antibacterial, and anti-inflammatory activities, promote wound healing mainly in diabetic foot ulcers management (DFUs), which is still considers as an enormous problem and also increases the amputation rates and medical costs (Vijayakumar et al., 2019). The AgNPs with highest percentage can reduce wound size increased collagen deposition, few macrophages, tissue edema, and more fibroblasts in albino rats (Kumar et al., 2018). Silver NPs (14 nm) coated bandages eradicated bacterial growth, reduced inflammation, scarring and accelerated the healing process (Cameron et al., 2018).Acceleration in the wound healing process and improvement in the wound contractions in thermally injured mice were achieved by the application of biosynthesized AgNP based ointments (Gong et al., 2018).Silver used in the dentistry field for the treatments of orthodontic, endodontic, restorative, prosthetic, periodontal. Along with that, silver has anti-caries (tooth decay) effect and antitumour effect on oral cavities. In dermatology field, silver is used for acne, eczema, fungal infections etc., for variant skin conditions. Silver nano dressings have the qualities of regenerative, effective, astringent and caustic potential. Also, AgNPs are applied in cardiology because of their antibacterial and anti-thrombogenic properties (Jasminka
Talapko et al., 2020).

Green synthesis of silver nanoparticles has advantages over the chemical and physical method as it is moneyspinning, eco-friendly, one-step method, easily scaled up for large-scale synthesis and does not require high pressure, energy, temperature and toxic chemicals for production(Abdul Ghani and Amin 1997, Kumar and Yadav 2009, Devendra Jain and Kothari 2014, Adebayo et al., 2014,ShabnumShaheen et al., 2017). Using microorganisms and enzyme have been suggested as possible eco-friendly alternatives (Mohanpuria et al., 2008). The plants or plant parts extract, which act as reducing and capping agents for nanoparticles synthesis, are more advantageous over other biological processes (Valli and Vaseeharan 2012), because they eliminate the elaborated process of culturing and maintaining of the cell, and can also be scaled up for large-scale nanoparticle synthesis (Saxena et al., 2012). Different parts of plant materials such as extracts (Mubarakali et al., 2011), fruit (Prathna et al., 2011), bark (Satishkumar et al., 2009), paddy husk (Reenal and Iruthayakalaiselvam, 2015), fruit peels (Bankar et al.,2010) root (Ahmad et al., 2010) and callus(Nabikhan et al., 2010) have been studied so far for the synthesis of silver, gold, platinum and titanium nanoparticles in several sizes and shapes (Gopinath et al.,2012).

Tagetes species are used in different areas like medicines, cosmetic preparation. Flowers have different colors and different fragrance. It has a strongly aromatic essential oil (Tagetes oil). It has quercetagetin, a glucoside of quercetagetin, phenolics, syringic acid, methyl-3, 5-dihydroxy-4-methoxy benzoate, quercetin, thienyl and ethyl gallate, terpines, carotenoids and other important phytochemical constituents. Also useful in fevers, epileptic fits (Ayurveda), astringent, stomachic, carminative, scabies, liver complaints and eyes treatments. The leaves are treated against piles, muscularpain, kidney troubles, ulcers, and also has following activity such as Anti-bacterial, Anti-microbial, hepatoprotective, Insecticidal, Mosquitocidal ,Nematicidal , Wound healing , Anti-oxidant, Analgesic and Larvicidal (Dixit Priyanka et al.,2013).10 to $90 \mathrm{~nm}$ spherical and hexagonal and irregular in shape Tagetes flower silver nanoparticles were synthesized and confirmed the presence of silver metal by getting maximum peak at $430 \mathrm{~nm}$ in UV-visible spectrum and performed its antimicrobial potential against Gram positive (Staphylococcus aureus and Bacillus cereus), Gram negative (Escherichia coli and Pseudomonas aeruginosa) bacteria and fungi (Candida glabrata, Candida albicans, Cryptococcae neoformans) (HemaliPadalia et al., 2014).Synthesized polydispersed, spherical silver nanoparticles of $20-50 \mathrm{~nm}$, with the average size of $30 \mathrm{~nm}$ using Tagetes leaves crude extract (Umesh et al., 2019). 
The presents investigation provides a simple, ecofriendly approach of sliver nanoparticles synthesis using Tagetes leaves extract and its bactericidal, antiinflammatory and wound healing activity in female Wistar albino rats.

\section{MATERIALS AND METHODS}

Experimental design: The experimental design is indicated in Fig.1.

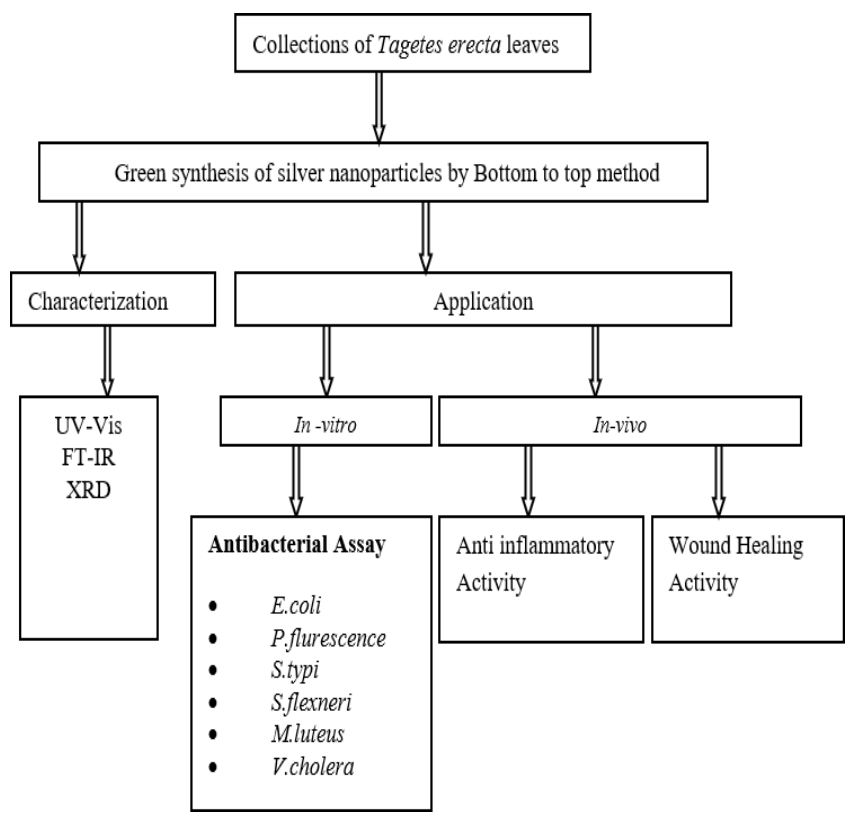

\section{Green synthesis of silver nanoparticles}

Tagetes leaves were collected and washed with tap water, followed by double distilled water to remove waste materials. $10 \mathrm{~g}$ of the fresh sample was mixed and boiled with $100 \mathrm{~mL}$ of double distilled water for 3 mins. After 10 mins, the extracts were transferred into conical flask and filtered thrice with Whatman No.1 filter paper to remove particulate matter for getting clear solution and stored $4^{\circ} \mathrm{C}$ refrigerated for further experiments. $0.02 \mathrm{mmol}$ aqueous solution of silver nitrate was prepared by adding $0.0338 \mathrm{~g}$ of the silver nitrate in the $100 \mathrm{~mL}$ double-distilled water. $5 \mathrm{ml}$ extract was mixed with $10 \mathrm{ml}$ aqueous silver nitrate solution under normal condition. The test tubes were sealed using cotton plugs and observed the colour change. The distinct colour change of the silver nitrate solution from colourless to grey colour after the reduction process indicates the formation of silver nanoparticles (Saxena et al., 2012).

Characterizations of synthesized silver nanoparticles Synthesized silver nanoparticles were confirmed by UV - Vis spectrophotometer at the wavelength of 250-600 nm (CHEMILINE CL - 1320 Spectrophotometer). Fourier transforms infrared (FTIR) spectrophotometer (Model (Shimazdu, India) was used to characterize the functional Group and composition of AgNP at a range of 4,000 to $400 \mathrm{~cm}^{-1}$. The suspension was subjected to centrifugation twice at $10,000 \mathrm{rpm}$ for 10 minutes each for collecting nanoparticles. After discarding the supernatant, the pellet was washed with $1 \mathrm{~mL}$ of doubledistilled water for removing the unwanted biological materials and then centrifuged twice, followed by drying on a watch glass at room temperature. The final AgNPs were stored at $4^{\circ} \mathrm{C}$ for further studies (Hemali et al., 2015). Phase formation of Silver nanoparticles was characterized by X-ray diffraction. Films of colloidal silver nanoparticle formed on Si (III) substrates by drop coating were used for X-ray-diffraction (XRD) study. The data were obtained using (RIGAKU - MINLFEEX $600)$. The fine structure of the compound was identified using the formula,

$\mathrm{D}=\mathrm{K} \lambda / \beta \cos \theta$

$\lambda-$ Is the $x$-ray wavelength

$\beta-$ Is the full width at half maximum (FWHM) and

$\theta-$ Is the diffraction angle)

Scanning Electron Microscopy (SEM) analysis was carried out using a JEOL JSM-6390 model at $20 \mathrm{kV}$. A thin carbon-coated film of the sample was formed by placing a small amount of sample on the copper grid. After removing extra moisture using blotting paper, the sample film on the SEM grid was dried under a mercury lamp for 5 minutes prior to analysis (Hemali et al., 2015).

Bactericidial activity of synthesized silver nanoparticles (Disc Diffuction Method, Heatly, 1944)

Invitro anti-bacterial activity was assayed by the Disc diffusion method, for Escherichia coli (ATCC25922) Micrococcus luteus (DSM1790), Solmonella typi (B10827), Bacilus cereus (M10) and Pseudomonas flurescences $(A H 2)$. Test pathogens supplied by the Basic Biomedical Science, Bharathidasan University, Trichy. A $0.3 \mathrm{ml}$ amount of synthesized silver nanoparticles was applied to $4 \mathrm{~mm}$ sterile disc. In the same way for control $0.3 \mathrm{ml}$ of amikacin was soaked in sterile disc. Both the discs were allowed to dry at room temperature. Pathogenic bacterial strains were inoculated in sterile broth and incubated at $37^{\circ} \mathrm{C}$ for $24 \mathrm{hrs}$. Pathogens were swabbed and placed on the surface of sterile petri dishes in $20 \mathrm{ml}$ of solidified nutrient agar. The control and the experimental discs were placed in the sterile solidified nutrient agar petri plates to assess the effect of extracts on pathogens. These agar plates were incubated at $37^{\circ} \mathrm{C}$ for $24 \mathrm{hrs}$ and the antibacterial activity was measured accordingly based on the inhibition zone around the disc. Each synthesis of silver nanoparticles were tested thrice for confirmation of activity.

\section{Animal study}

The experimental female Wistar albino rats (120$150 \mathrm{gm})$ were acclimatized for 1 week prior to experi- 
mentation. They were reared in polypropylene cages with sterile husk materials and fed with a standard pellet diet and water. They were raised under the controlled environmental conditions of $23^{\circ} \mathrm{C} \pm 2^{\circ} \mathrm{C}$ and relative humidity of $55 \% \pm 10 \%$ on a 12 -hour light/dark cycle. The animal experimental protocols used in this study were recognized by Govt. of Tamilnadu, approved by the Pharmacy Council of India, New Delhi and Use Committee of SankaralingamBhuvaneshwari College of Pharmacy at Anaikuttam, Sivakasi (Ref:SBCP/2020-21/ CPCSEA/IAEC/I(3)/F16/151) and followed the norms prescribed by the Ministry of Social Justice and Empowerment Committee, Government of India, NewDelhi.

\section{Anti-inflammatory activity}

The anti-inflammatory activity of biosynthesized Ag-NPs was evaluated in Wistar albino adult female rats using the standard carrageenan-induced paw edema method in vivo condition (Winter et al., 1962). The experimental animals were randomly divided into Four groups $(n=4)$. Group I-Positive control (Water only), Group II-Standard Diclofenac $20 \mathrm{mg} / \mathrm{kg}$. Group III-TLSNP $200 \mathrm{mg} / \mathrm{kg}$, Group IV-TLSNP $400 \mathrm{mg} / \mathrm{kg}$. They were fasted overnight with free access to water prior to treatment. All mice were given carrageenan $(10 \mathrm{mg} / \mathrm{kg}$; Hi-Media, Mumbai, India) to induce inflammation. Standard Oral administration of Diclofenac and biosynthesized AgNPs was performed 30 minutes before the carrageenan injection in the right hind paws of experimental mice. And then, Plethysmometer (Plethysmometer (Panlab, LE7500, USA) was used to measurethe volume of the paw at intervals of $0,1,2,3$, and 4 hours for analyzing the anti-inflammatory activity of Ag-NPs in vivo condition. The change in paw volume was taken as actual oedema volume. The percent of inhibition was calculated using the formula:

Percentage of inhibition=100(1-Vt/Vc) ............. Eq. 1 Where $V t$ is the increase in paw volume of rats treated with the sample drug and $V$ cis the increase in paw volume of the positive control group.

\section{Wound healing activity}

In this experiment, animals were categorized into four groups $(n=4)$ and fed with normal food and water. Each Group contained four animals for the test. Group I- Positive control (simple ointment), Group II-Negative control (Povidone-iodine ointment), Group III-TLSNP 5\% (Tagetes leaves silver nanoparticles), Group IV-TLSNP 10\% (Tagetesleaves silver nanoparticles). All the experiment animals underwent the following dorsal surgery procedure. The animals were anaesthetized, followed by an injection of 2,2,2- Tribromoethanol, Aldrich, $25 \mathrm{mg} / 100 \mathrm{~g}$ body weight through intraperitoneal injection. After removing the hair from the dorsal skin of the animal, $15 \mathrm{~mm}$ diameter size of the wound was made. Povidone-iodine was used as a topical anti-infective in the control animal. The wound received topical application of silver nanoparticles. Immediately after surgery, $0.4 \mathrm{ml}$ of veterinary pentabiotic was given to all the animals via intra-muscular. The effectiveness of the sample is studied by measuring the reduction in the diameter of the wound in all the animal belonging to four different groups on $10^{\text {th }}$ and $20^{\text {th }}$ day.

\section{Statistical analysis}

All experiments were performed with groups of four animals each and the results were expressed as mean \pm the standard error. All data were analyzed using Statistical Package for the Social Sciences 17.0 software (SPSS Inc., Chicago, IL, USA).

\section{RESULTS AND DISCUSSION}

\section{Visual observations of synthesized nanoparticle}

The colour of the solution changed from brown colour depending on the extract concentration indicating silver nanoparticles formation as the colour change observed was due to excitation of surface Plason vibration in the silver nanoparticles. Silver nanoparticles exhibited brown colour in an aqueous solution due to excitation of surface plasmon resonance. On mixing the Tagetes leaves extract with an aqueous solution of the silver ion complex, a change in the colour from light green to brown precipitate was obtained after 2 minutes of incubation with silver nitrate (Fig. 2). The fresh suspension of Lemon (Citrus aurantifolia), Orange (Citrus sinensis) and Tomato (Solanumly copersicum), was yellowish brown colour (Anil Ramdas Shet et al., 2015).

\section{Characterizations of synthesized nanoparticles}

Ultraviolet spectroscopy is an indirect method to examine the bioreduction of AgNP from an aqueous $\mathrm{AgNO}_{3}$ solution. UV-Vis absorption spectrum of the Tagetes leaves extract was obtained at $428 \mathrm{~nm}$ due to the excitation of surface plasmon vibration in nanoparticles and confirm the synthesis of silver nanoparticles (Fig. 3). The concentration of the olive leaf extract increases, the absorption peak gets more sharpness and blue shift was observed from 458-441 nm (Kahalil et al., 2012)

\section{FT-IR analysis}

In FTIR analysis of Tagetes leaves silver nanoparticle, the following prominent bands of absorbance were observed at $1380 \mathrm{~cm}^{-1}, 885 \mathrm{~cm}^{-1}, 1100 \mathrm{~cm}^{-1}$, $2840 \mathrm{~cm}^{-1}$ and $1566 \mathrm{~cm}^{-1}$ correspond to $\mathrm{S}=\mathrm{O}, \mathrm{C}=\mathrm{C}$, $\mathrm{C}=\mathrm{O}, \mathrm{C}-\mathrm{H}$ and $\mathrm{C}=\mathrm{C}$ stretching vibrations of sulfate, alcohol, and alkene are present in the Tagetes leaves extracts. They acted as both capping agent as well as stabilizing agent (Fig. 4). The Ag nanoparticles synthesized using olive leaf extract, the FT-IR band observed at $3409 \mathrm{~cm}^{-1}$ characteristic of the $\mathrm{O}-\mathrm{H}$ and $\mathrm{C}=\mathrm{O}$ stretching modes for the $\mathrm{OH}$ and $\mathrm{C}=\mathrm{O}$ groups 

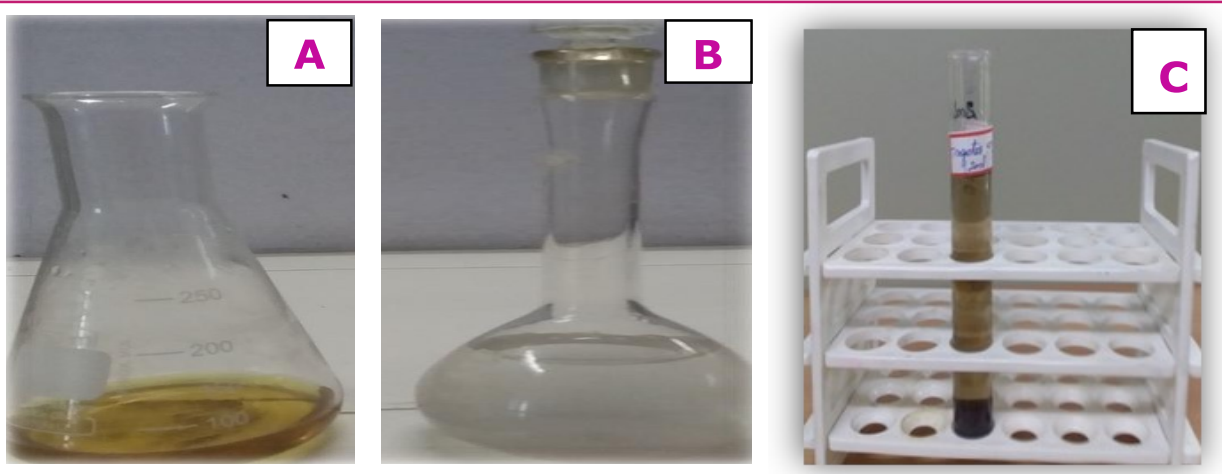

Fig. 2. Green Synthesis of silver nanoparticles from Tagetes leaves extract. Note: $A=$ Tagetes leaves extract before adding $\mathrm{AgNO}_{3}$, $\mathrm{B}=$ Silver Nitrate solution., $\mathrm{C}=$ Tagetes leaves extract after 20 min of incubation.

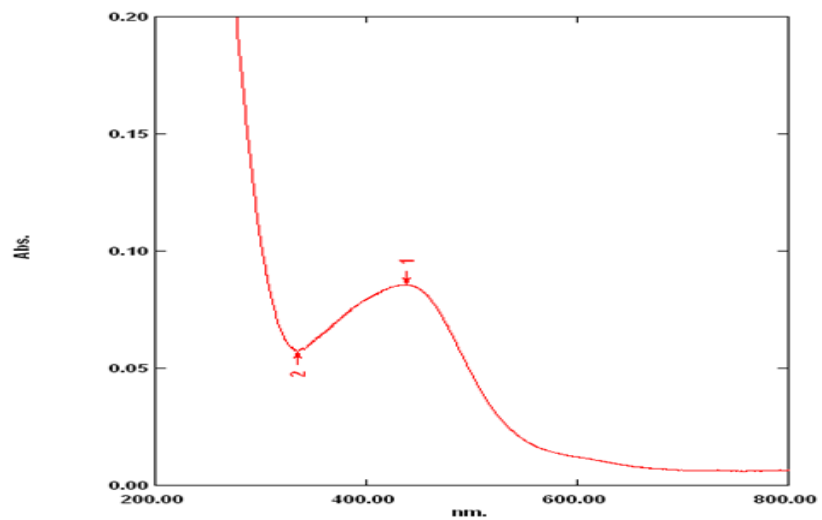

Fig. 3. UV-Vis spectrum of Tagetes leaves silver nanoparticles recorded at room temperature.

possibly of oleutropin, apigenin-7-glucoside and luteolin -7-glucoside nanoparticles synthesized using olive leaf extract, theFT-IR band observed at $3409 \mathrm{~cm}^{-1}$ characteristic of the $\mathrm{O}-\mathrm{H}$ and $\mathrm{C}=\mathrm{O}$ stretching modes for the $\mathrm{OH}$ and $\mathrm{C}=\mathrm{O}$ groups possibly of oleutropin, apigenin-7glucoside and luteolin-7-glucoside (Kahalil et al., 2012).

\section{XRD analysis}

Three Bragg's reflections were observed in the XRD pattern in the $2 \theta$ range at $38.1,77.4,46.4,44.6$ and 64.5 , which correspond to the miller indices of (111), (311), (200), (200) and (220) respectively. Hence, these XRD patterns thus clearly indicated the well crystalline AgNPs formed and it is well-matched to their standard JCPDS values. In general, the width of XRD peaks is related to crystallite size. The Debye-Scherrer equation was used to determine the average crystallite

diameter from half width of the diffraction peaks:

$$
D=(k \lambda) /(\beta \cos \theta)
$$

Where, $D$ is mean crystallite size of the powder; $\lambda$ is the wavelength of Cuka; $\beta$ is the full width at halfmaximum; $\theta$ is the Bragg diffraction angle; and $k$ is a constant. The (111) plane was chosen to calculate crystalline size. From the Debye-Scherrer equation, the average crystallite size of AgNP synthesized is found to be $27.2 \mathrm{~nm}$ (Fig. 5).

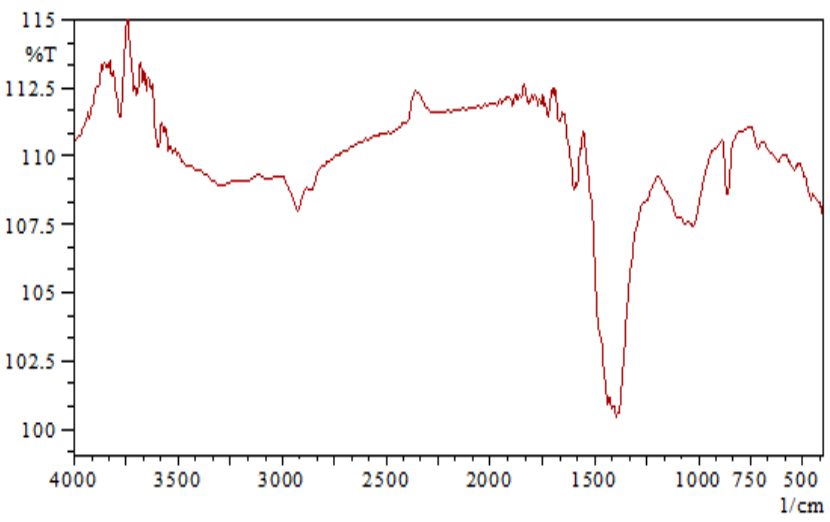

Fig. 4. FT-TR spectra for Tagetes erecta leaves extract reduced silver nanoparticles.

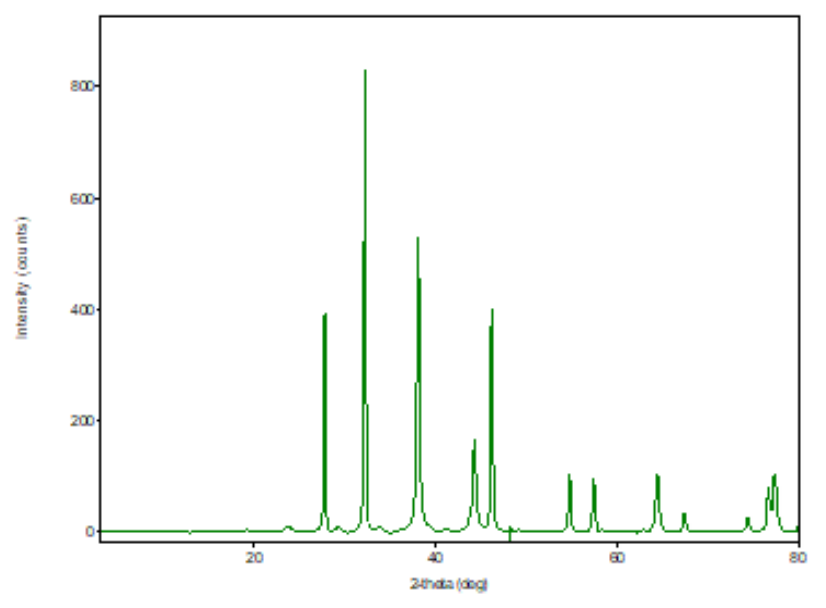

Fig. 5. XRD pattern for Tagetes erecta leaves extract reduced silver nanoparticles.

\section{SEM analysis}

Fig. 6. shows the SEM images of (a) low and (b) high magnifications of as-prepared green synthesized silver nanoparticles (AgNPs). The images clearly show that the AgNPs were mostly agglomerated spherical nanoparticles and different size distribution with an average diameter value of about $15.5 \mathrm{~nm}$. The morphology of the agglomerated nanoparticles surfaces has great impact on the biological applications. 


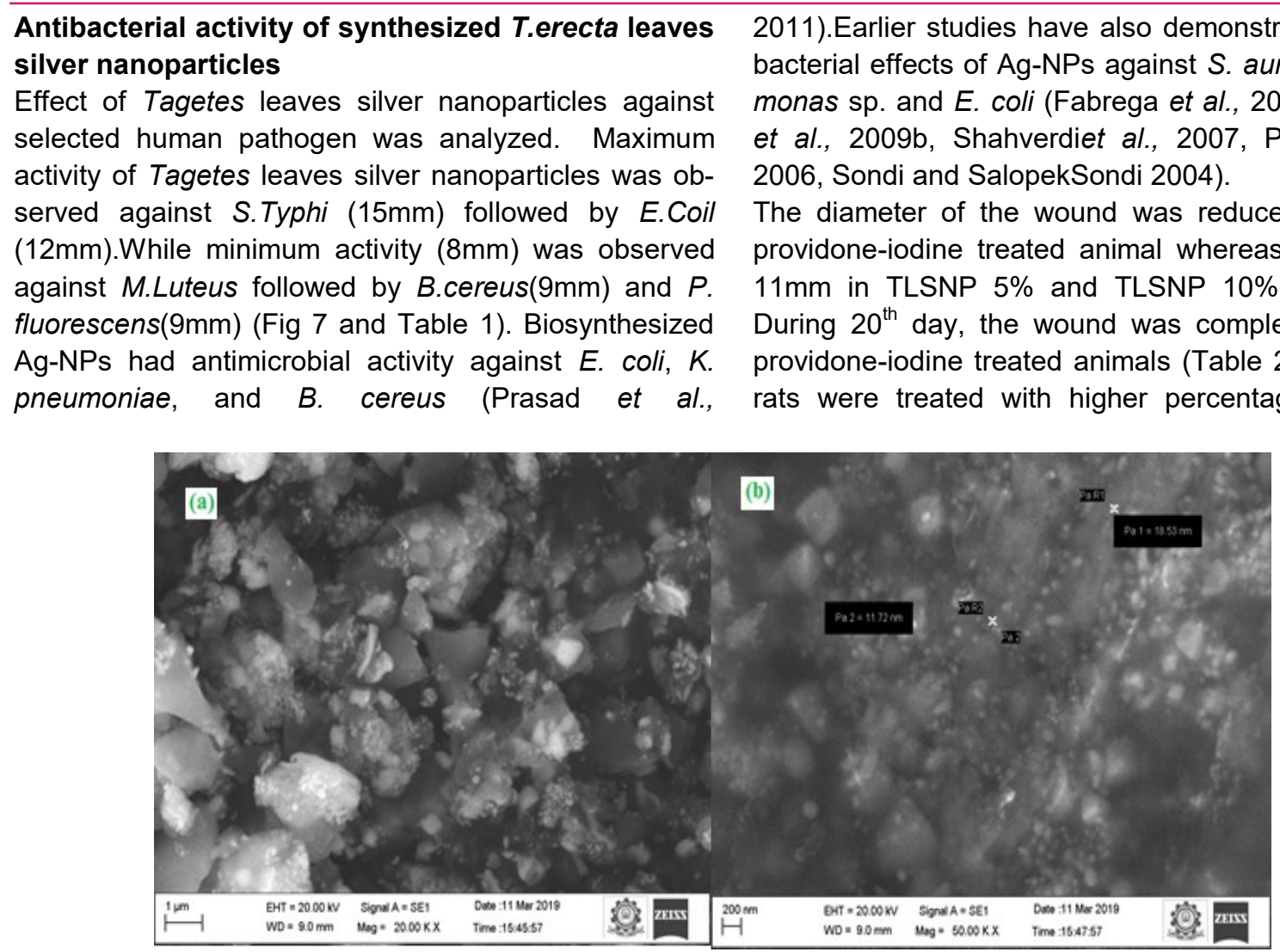

Fig. 6. SEM image of (a) High magnification of silver nanoparticles and (b) low magnification of silver nanoparticles.

Table 1 Effect of Tagetes erecta leaves extract silver nanoparticles against selected human pathogen .

\begin{tabular}{lllll}
\hline S. NO & Pathogens & PC & NC & TLSNP \\
\hline $\mathbf{1}$ & M.Luteus & $40 \mathrm{~mm}$ & $5 \mathrm{~mm}$ & $8 \mathrm{~mm}$ \\
$\mathbf{2}$ & S.Typhi & $37 \mathrm{~mm}$ & $6 \mathrm{~mm}$ & $15 \mathrm{~mm}$ \\
$\mathbf{3}$ & E.Coli & $40 \mathrm{~mm}$ & $6 \mathrm{~mm}$ & $12 \mathrm{~mm}$ \\
$\mathbf{4}$ & B.Cereus & $35 \mathrm{~mm}$ & $6 \mathrm{~mm}$ & $9 \mathrm{~mm}$ \\
$\mathbf{5}$ & P.fluorescens & $43 \mathrm{~mm}$ & $5 \mathrm{~mm}$ & $9 \mathrm{~mm}$ \\
\hline
\end{tabular}

Note: PC- Positive Control., NC-Negative control., TLSNPTagetes Leaves Silver Nano Particles.

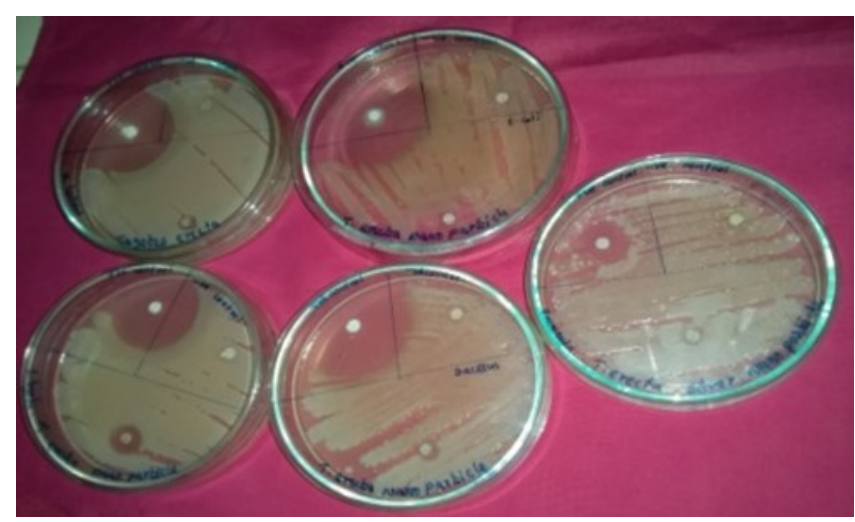

Fig. 7. Effect of Tagetes erecta leaves extract silver nanoparticles against selected human pathogen .

Table 2 Wound healing Activity of synthesized silver nanoparticles.

\begin{tabular}{lllll}
\hline $\begin{array}{l}\text { Animal } \\
\text { Group }\end{array}$ & Treatment & O Day & $\mathbf{1 0}^{\text {th }}$ Day & $\mathbf{2 0}^{\text {th }}$ Day \\
\hline Group-I & PC & $515.05 \pm 8.6787$ & $405.975 \pm 31.6338$ & $218.025 \pm 34.3466$ \\
Group-II & NC & $512.775 \pm 12.7440$ & $177.375 \pm 9.3770$ & $26.95 \pm 7.6776$ \\
Group-III & TLSNP 5\% & $515.7 \pm 7.4815$ & $407.1 \pm 18.5982$ & $276.7 \pm 11.7688$ \\
Group-IV & TLSNP 10\% & $512.775 \pm 13.1386$ & $202.85 \pm 5.7049$ & $77.925 \pm 10.9998$ \\
\hline
\end{tabular}

Note: PC-Positive Control (simple ointment)., NC-Negative Control (Povidine iodine ointment)., TLSNP-Tagetes Leaves Silver Nano Particles. 


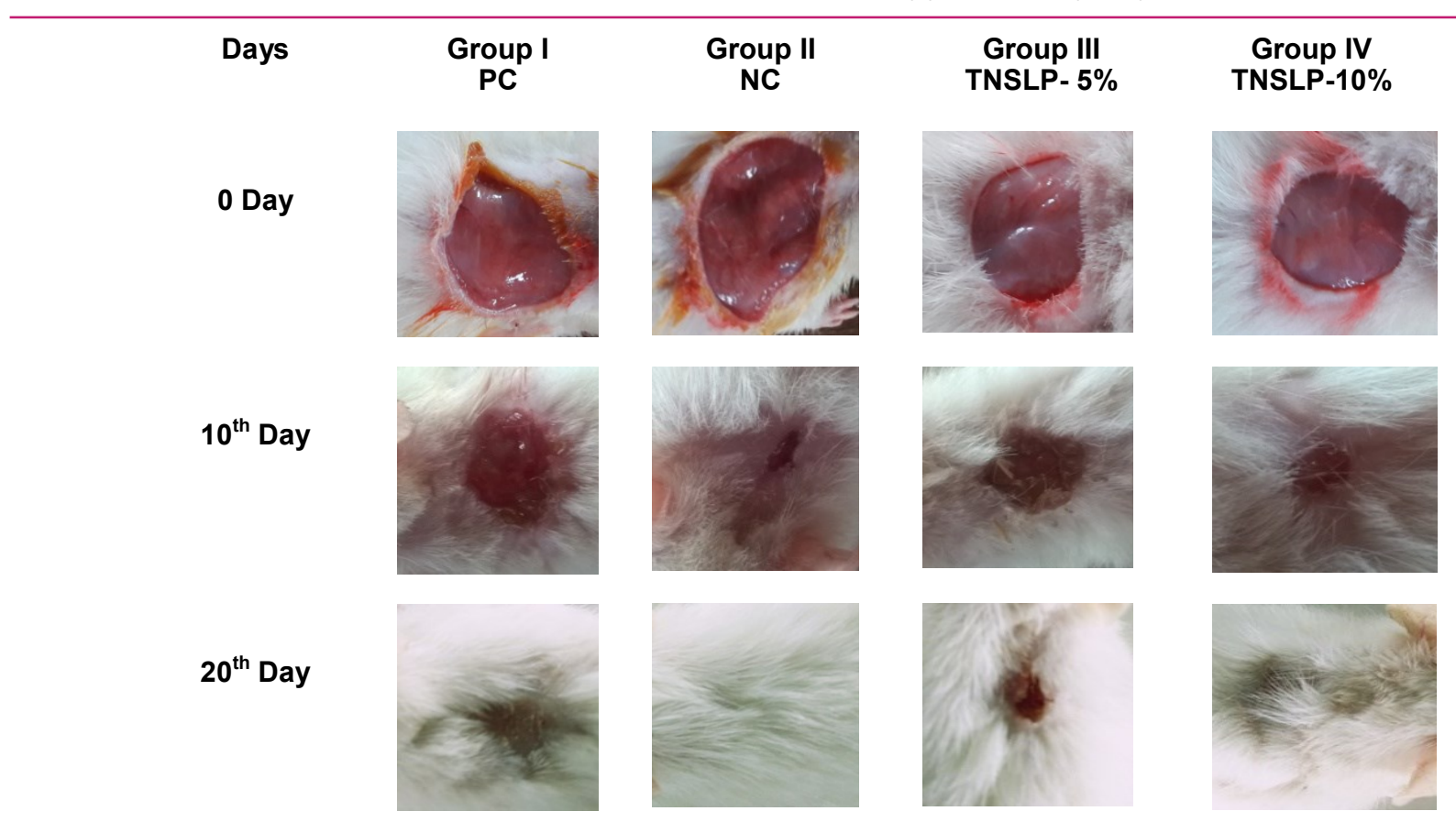

Fig. 8. Wound Healing Activity of synthesized silver nanoparticles Note: PC-Positive Control (simple ointment)., NCNegative Control (Povidine iodine ointment)., TLSNP-Tagetes Leaves Silver Nano Particles.

showed reduced wound area due to increased collagen deposition, few macrophages, tissue edema, and more fibroblasts (Kumar et al., 2018).

\section{Anti-inflammatory activity}

Inflammation, proliferation, and tissue remodeling are wound healing processes. The wound stimulates inflammation and releasing of pro-inflammatory cytokines. With the help of macrophages granulations, tissue formation and angiogenesis are taking place during proliferation. Tissue remodeling process consists of the removal of damaged tissue and remodeling of extracellular matrix (Frankova et al., 2016). Nanosilver treatment has played a important role in wound healing (Tian et al., 2007, Wong et al., 2009, Pothireddy et al., 2016, Pourali and Yahyaei 2016, Pourali et al., 2016, Orlowski et al., 2018).Short term inflammation caused by stimulation has been found to accelerate the healing process (Frankova et al., 2016, Orlowski et al., 2018). In the present study, both doses of silver nanoparticles exhibited anti-inflammatory activities by inhibiting oedema. A high reduction in the oedema formation observed in the animal group which were treated with Standard Diclofenac $20 \mathrm{mg} / \mathrm{kg}$ followed by TLSNP $400 \mathrm{mg} / \mathrm{kg}$ and TLSNP 200mg/kg (Table 3).

\section{Conclusion}

Colloidal Ag-NPs can be synthesized by simple, nonhazardous methods, and biosynthesized Ag-NPs using Tagetes leaves extract had significant therapeutic properties. This work evidently confirmed that silver nanoparticles mediated Tagetes could be considered a potential source for anti-inflammatory and wound healing drugs.

Table 3. Anti-inflammatory Activity $\left(\mathrm{mm}^{2}\right)$ of synthesized silver nanoparticles.

\begin{tabular}{|c|c|c|c|c|c|c|}
\hline $\begin{array}{l}\text { Animal } \\
\text { Groups }\end{array}$ & Dosage & Ohrs & $1 \mathrm{hrs}$ & $2 \mathrm{hrs}$ & $3 \mathrm{hrs}$ & $4 \mathrm{hrs}$ \\
\hline Group I & Control & $0.1425 \pm 0.011$ & $0.165 \pm 0.038$ & $0.1925 \pm 0.037$ & $0.225 \pm 0.03$ & $0.23 \pm 0.0365$ \\
\hline Group-II & $\begin{array}{l}\text { Standard } \\
\text { Diclofenac } \\
\text { 20mg/kg } \\
\text { TLSNP }\end{array}$ & $0.1725 \pm 0.059$ & $0.12 \pm 0.0432$ & $0.0775 \pm 0.044$ & $0.035 \pm 0.041$ & $0.0225 \pm 0.019$ \\
\hline Group-III & $\begin{array}{l}200 \mathrm{mg} / \mathrm{kg} \\
\text { P.O } \\
\text { TLSNP }\end{array}$ & $0.1725 \pm 0.052$ & $0.145 \pm 0.047$ & $0.1275 \pm 0.041$ & $0.115 \pm 0.047$ & $0.1125 \pm 0.055$ \\
\hline Group-IV & $\begin{array}{l}400 \mathrm{mg} / \mathrm{kg} \\
\text { P.o }\end{array}$ & $0.19 \pm 0.036$ & $0.14 \pm 0.036$ & $0.1 \pm 0.036$ & $0.0575 \pm 0.034$ & $0.05 \pm 0.043$ \\
\hline
\end{tabular}

Note: TLSNP-Tagetes Leaves Silver Nano Particles. 


\section{REFERENCES}

1. Abdul Ghani, A.S. and Amin, R. (1997). Effect of aqueous extract of Commiphoraopobalsamum on blood pressure and heart rate in rats. J. Ethnopharmacol., 57(3):219-222.

2. Adebayo, E.A. Oloke, J.K. andAina, D.A. (2014) Bora TC Antioxidant and nutritional importance of some Pleurotus species. JMBFS. 3(4):289-294.

3. Ahmad, N. Sharma, S.Alam, MK. Singh, VN. Shamsi SF.andMehta, BR.(2010). Rapid synthesis of silver nanoparticles using dried medicinal plant of basil Colloids and Surfaces. B: Biointerfaces. 81:81-86.

4. Anil RamdasShet, Pritam Ghose, Laxmikant Patil, and VeerannaHombalimath. (2015). A Preliminary study on green synthesis and antibacterial activity of silver nanoparticles. Int. J. Curr. Biotechnol., 3(2), 1-6.

5. Bankar, A. Joshi, B. Kumar, A.R. and Zinjarde, S. (2010). Banana peel extract mediated novel route for the synthesis of silver nanoparticles. Colloids and Surfaces APhysicochemical and Engineering Aspects, 368:58-63.

6. Baygar, T. Sarac, N., Ugur, A. and Karaca, I.R. (2018). Antimicrobial characteristics and biocompatibility of the surgical suturecoated with biosynthesized silver nanoparticles. Bioorg. Chem.,8 (6), 254-258.

7. Beyth, N. Houri Haddad, Y. Domb, A. Khan, W. and Hazan, R. (2015). Alternative antimicrobial approach: Nanoantimicrobial materials. Evid. Based Compl. Alt., 246012.

8. Blacklow, S.O., Li, J. Freedman, B.R. Zeidi, M. Chen, C. and Mooney, DJ.(2019). Bioinspired mechanically active adhesive dressings to accelerate wound closure. Science Advances, 5(7),3963.

9. Burdus, A.C.Gherasim, O.Grumezescu, A. M.Mogoanta, L.Ficai, A.and Andronescu, E. (2018). Biomedical applications of silver nanoparticles; An up-to-date overview. Nanomaterials, 8, 681 .

10. Cameron, SJ. Hosseinian, F. and Willmore, WG.(2018). A current overview of the biological and cellular effects of nanosilver. Int. J. Mol. Sci. 19:2030.

11. Dakal, TC. Kumar, A. Majumdar, RS. and Yadav, V (2016). Mechanistic basis of antimicrobial actions of silvernanoparticles. Front. Microbiol. 7I, 1831.

12. Deshmukh, SP. Patil, SM.Mullani,and SB.Delekar, SD. (2019). Silver nanoparticles as an effective disinfectant: A review. Mater.Sci.Eng.C Mater.97,954-965.

13. Devendra Jain, and Kothari, SL. (2014). Green synthesis of silver nanoparticles and their application in plant virus inhibition. J Mycol. Plant Pathol., 44:21-24.

14. Dixit Priyanka, Tripathi Shalini, Verma Kumar Navneetet. (2013). A brief study on marigold (Tagetes species): A review. International Research Journal of Pharmacy, 4(1), 43-47.

15. Fabrega, J. Fawcett, SR. Renshaw, JC.and Lead, JR (2009b). Silver nanoparticle impact on bacterial growth: effect of $\mathrm{pH}$, concentration and organic matter. Environ Sci Tech., 43(19),7285-7290.

16. Fabrega, J. Renshaw, J.C. and Lead, J.R. (2009a). Interactions of silver nanoparticles with Pseudomonas putida biofilms. Environ Sci Technol., 43(23):9004-9009.

17. Frankova, J.Pivodova, V. Vagnerova, H. Juranova, J.and Ulrichova, J.(2016). Effects of silver nanoparticles on primary cell cultures of fibroblasts and keratinocytes in a woundhealing model. J. Appl. Biomater. Funct. Mater.,14, 137-142.
18. Gong, C.P. Li. S.C. and Wang, R.Y.(2018). Development of biosynthesized silver nanoparticles-based formulation for treating wounds during nursing care in hospitals. $J$. Photochem. Photobiol. B., 183:137-141.

19. Gopinath, V.Mubarakali, D. Priyadarshini, S. Priyadarshini, NM.Thajuddin, N. and Velusamy, P. (2012). Biosynthesis of Silver nanoparticles from Tribulus terrestris and its antimicrobial activity: a novel biological approach. Colloids and Surfaces, B: Biointerfaces, 96, 6974.

20. Haider, A.and Kang, IK. (2015). Preparation of silver nanoparticles and their industrial and biomedical applications:A comprehensive review. Adv. Mater. Sci. Eng.,16 5257.

21. Heatly NG. (1944). A method for the assay of pencillin. Biochem. J., 38,61-65.

22. Hemali, P. Pooja, and M, Sumitra, C.(2015). Green synthesis of silver nanoparticles from marigold flower and its synergistic antimicrobial potential. Arab J Chem., 8(5),732-741.

23. HemaliPadalia, Pooja Moteriya, andSumitra Chanda. (2014). Green synthesis of silver nanoparticles from marigold flower and its synergist antimicrobial potential. Arabian Journal of Chemistry,10, 1878- 5352.

24. Jasminka Talapko, Tatjana Matijevic, Martina Juzbasic, Arlen AntolovicPozgain, and Ivana Skrlec (2020). Antibacterial activity of silver and its application in Dentistry, Cardiology and Dermatology.Microorganisms, 8,1400.

25. Kahalil, M.H. Ismail, E. H. and El-Magdob, F.(2012). Biosynthesis of Au nanoparticles using olive leaf extract. Arab. J. Chem., 5,431-437.

26. Kumar, SSD. Rajendran, NK. Houreld, NN. andAbrahamse, H.(2018). Recent advances on silver nanoparticle and biopolymer-based biomaterials for wound healing applications. Int. J. Biol. Macromol.,115,165-175.

27. Kumar, V. and Yadav, SK.(2009). Plant-mediated synthesis of silver and gold nanoparticles and their applications. Journal of Chemical Technology and Biotechnology, 84:151-157.

28. Liao, C. Li, Y. and Tjong, SC. (2019). Bactericidal and cytotoxic properties of silver nanoparticles. Int. J. Mol. Sci., 20,449.

29. Mathur, P. Jha, S. Ramteke, S.and Jain, NK. (2018). Pharmaceutical aspects of silver nanoparticles. Artif. Cells Nanomed. Biotechnol., 46, 115-126.

30. Mcdonnell, G. and Russell, AD. (1999). Antiseptics and disinfectants Activity, action, and resistance. Clin. Microbiol. Rev., 12, 147-179.

31. Mihai, MM. Dima, MB. Dima, B. and Holban, AM.(2019). Nanomaterials for wound healing and infection control. Materials Basel., 12(13),2176.

32. Mohanpuria, P. Rana, NK. and Yadav, SK. (2008). Biosynthesis of nanoparticles: technological concepts and future applications. Journal of Nanoparticle Research. 10:507-517.

33. Mubarak Ali, D. Thajuddin, N. Jeganathan, K. and Gunasekaran, M. (2011). Plant extracts mediated synthesis of silver and gold nanoparticles and its antibacterial activity against clinically isolated pathogens Colloids and Surfaces, B: Biointerfaces, 85, 360-365.

34. Nabikhan, A. Kandasamy, K. Raj, A.and Alikunhi, N. (2010). Synthesis of antimicrobial silver nanoparticles by callus and leaf extracts from saltmarsh 
plant, Sesuviumportulacastrum. Colloids and Surfaces, $B$. Biointerfaces. 79:488-493.

35. Orlowski, P. Zmigrodzka, M. Tomaszewska, E. Ranoszek Soliwoda, K. Czupryn, M. Antos-Bielska, M. Szemraj, J. Celichowski, G. Grobelny, J. and Krzyzowska, M.(2018). Tannic acid-modified silver nanoparticles for wound healing: The importance of size. Int. J. Nanomed. 13, 9911007.

36. Panacek, A.Kvitek, L.and Prucek, R.(2006). Silver colloid nanoparticles: synthesis, characterization and their antibacterial activity. J Phys Chem B., 110(33), 16248-16253.

37. Pothireddy, S.Kaliki, A. Mekapogu, AR.Yegireddy, M. Pagadala, E. P. and Prasad, TNVKV.(2016). Evaluation of the Wound Healing Efficacy of Chemical and Phytogenic Silver Nanoparticles. IET Nanobiotechnol., 10, 340-348.

38. Pourali, P.and Yahyaei, B. (2016). Biological production of silver nanoparticles by soil isolated bacteria and preliminary study of their cytotoxicity and cutaneous wound healing efficiency in rat. J. Trace Elem. Med. Biol., 34, 22-31.

39. Pourali, P.Razavian Zadeh, N. andYahyaei, B. (2016). Silver nanoparticles production by two soil isolated bacteria, Bacillus thuringiensis and Enterobacter cloacae, and assessment of their cytotoxicity and wound healing effect in rats. Wound Repair Regen., 24, 860-869.

40. Prasad, TNVKV. Elumalai, EK.and Khateeja, S.(2011). Evaluation of the antimicrobial efficacy of phytogenic silver nanoparticles. Asian Pac J Trop Biomed., 82-85.

41. Prathna, TC. Chandrasekaran, N. Raichur, AM.and Mukherjee, A.(2011). Biomimetic synthesis of silver nanoparticles by Citrus limon (lemon) aqueous extract and theoretical prediction of particle size. Colloids and Surfaces, B: Biointerfaces., 82,152-159.

42. Reenal, M. andlruthayaKalai Selvam, S.(2015). Green Synthesis and Antibacterial activity of Silver Nanoparticles using Oryza Sativa Husk Extract. International Research Journal of Environment sciences., 4(5):68-72.

43. Satishkumar, M. Sneha, K. Won, SW. Cho, CW. Kim, S. and Yun, YS. (2009). Cinnamon zeylanicum bark extract and powder mediated green synthesis of nano-crystalline silver particles and its antibacterial activity.Colloids and Surfaces, B: Biointerfaces., 73:332-338.

44. Saxena, A. Tripathi, RM. Zafar, F.and Singh, P. (2012). Green synthesis of silver nanoparticles using aqueous solution of Ficus benghalensis leaf extract and characterization of their antibacterial activity. Materials Letters., 67, 91-94.

45. Shabnum Shaheen, Uzma Hanif, Farah Khan, Mehwish
Jaffer, Sobia Ilyas, Zeb Siddique, Tehreema Iftikhar, Samina Sarwar, Sana Khalid and Saiqalshtiaq.(2017). Study of Systematic Application of morpho palynological characterization of medicinal plants. Transylvanian Review, Vol 15,(19).

46. Shahverdi, AR.Fakhimi, A.Shahverdi, HR.and Minaian, S. (2007). Synthesis and effect of Silver nanoparticles on the antibacterial activity of different antibiotics against Staphylococcus aureus and Escherichia coli. NanomedNanotechnol., 3(2), 168-171.

47. Shang, L. Nienhaus, K. and Nienhaus, GU.(2014). Engineered nanoparticles interacting with cells: Size matters. J. Nanobiotechnol.12.

48. Sondi, I.and SalopekSondi, B. (2004).Silvernanoparticles as antimicrobial agent: a case study on $E$. coli as a model for Gram-negative bacteria. J Colloid Interface Sci., 275 (1), 177-182.

49. Tian, J. Wong, KKY. Ho, CM. Lok, CN. Yu, WY. Che, CM. Chiu, JF.and Tam, PKH.(2007). Topical delivery of silver nanoparticles promotes wound healing. Chem. Med. Chem., 2, 129-136.

50. Umesh, P. Dhuldhaj shivaji, D. Deshmukh Aniket, K. Gade, Madhu Yashpal and Mahendra, K.(2019).Tagetes erecta mediated phytosynthesis of silver nanoparticles: an ecofriendly Approach. Nusantara Bioscience, 11(1), 2087 -3956 .

51. Valli, JS. and Vaseeharan, B. (2012). Biosynthesis of silver nanoparticles by Cissus quadrangularis extracts. Materials Letters., 82, 171-173.

52. Vijayakumar, V. Samal, SK. Mohanty, and S. Nayak, SK. (2019). Recent advancements in biopolymer and metal nanoparticle-based materials in diabetic wound healing management. Int.J.Biol. Macromol., 122,137-148.

53. Wang, L. Hu, C.and Shao, L. (2017). The antimicrobial activity of nanoparticles: Present situation and prospects for the future. Int. J. Nanomed.,12,1227-1249.

54. Wei, L. Lu, J. Xu, H. Patel, A. Chen, ZS. and Chen, G.(2015). Silver nanoparticles: synthesis, properties and therapeutic applications. Drug. Discov. Today., 20,595-601.

55. Winter, CA.Risley,and EA.Nuss, GW.(1962). Carrageenan -induced edema in hind paw of rats as an assay for antiinflammatory drugs. Proc. Soc. Exp. Biol. Med., 111, 544547.

56. Wong, KKY. Cheung, SOF. Huang, L.Niu, J. Tao, C. Ho, CM. Che, CM.and Tam, PKH.(2009). Further evidence of the anti-inflammatory effects of silver nanoparticles. Chem. Med. Chem., 4,1129-1135. 